可視化情報 Vol.23 Supp1. No.1（2００３年 7 月）

B 204

磁界分布可視化法とその応用

藤枝 直樹ㅇ, 早野 誠治, 齋藤 兆古（法政大学 大学院）

堀井 清之(白百合女子大学)

\title{
Visualizing Methodology of Magnetic Vector Field and Its Applications
}

\author{
Naoki FUJIEDA ${ }^{\circ}$, Seiji HAYANO, Yoshifuru SAITO \\ Kiyoshi HORII
}

\begin{abstract}
Visualization of the vector fields is usually carried out by means of the vector arrow map. However, this conventional visualizing methodology to the vector fields is not applicable to image cognition method, because most of the image cognition method is applicable to the scalar images. To overcome this difficulty, we have previously proposed that the vector fields are visualized as the color images by projecting the $x, y$, and $z$ components in each of the vectors to the red, green, and blue components of light, respectively. By means of this visualizing methodology, we have succeeded in carrying out the nondestructive inspection of various electrical as well as electronic devices in a quite efficient manner.

However, this visualizing methodology of vector fields has the problem that the visualized images always depend on the reference coordinate system.

In this paper, we propose a technique of how to decide reference coordinate system for visualizing the vector fields as the scalar color images. Further, visualized images of the practical magnetic field distributions by our method are demonstrated.
\end{abstract}

Keywords: Reference coordinates, Magnetic field visualization, Vector field

\section{1. まえがき}

21 世紀に入り、パーソナルコンピュータ・携帯電話 を代表とする、小型軽量電子機器の個人レベルの普及が 著しい, 小型電子機器の普及恃電子回路の高密度実装化 技術の向上を意味することに他ならない，電子回路の高 密度実装化にはプリント基板技術の進歩が大きく貢献し ている.しかし、電子機器の小型軽量化は、電子機器か ら放射される電磁界の削減を意味しない，電子機器を駆 動するに注必然的に電流が流れ、電子機器周辺へ磁界を 放射する。この代表が携帯電話であろう。また、電子機 器の小型軽量化は配線の短縮化を可能とするプリント基 板の実装技術のみならず半導体の高密度集積化が大きな 貢献をしている．究極の配線技術であるプリント基板と 半導体の高密度集積化によって現代の小型軽量電子機器 が開発され、個人レベルまで小型軽量電子機器の普及が 促され、その結果として、通信や情報管理に大きな利便 性を与えた反面、小型化故に機器の検查および不良部位
の特定が困難になってきている事実は否めない。

以上のような現状に鑑み、我々は、小型軽量電子機器 周辺の放射磁界を可視化し画像認識技術と組み合わせる ことで、放射電磁界の指向性や強度評価、さらに検查工 程の全自動化などを究極の目標として、ベクトル場の可 視化技術を開発してきた。1，2)

従来、筆者らが開発したベクトル場の可視化は、予め 局所的に测定されるべクトルの基準座標が与えられてい ることを前提とした．具体的には、基準座標を既知とし て測定された磁界の三方向成分を光の R,G,B 成分に対 応させ、磁界分布をカラーイメージとして表現し、画像 認識技術を適用し、電子回路素子の健全性を評価した 1 . さらに、ベクトル場の基準座標の変化をある特定範囲へ 限定するが、测定の自由度を改善した。2)

本稿では、より大きな局所的ベクトル場測定の自由度 得るため、測定されたベクトル場から、ベクトル場の可 視化画像が不変と成る基準座標の決定法を提案する.

測定誤差を含まないシミュレーションでは、本稿で提 
案する方法は一意的な可視化画像を生成するベクトル場 の基準座標決定に成功した。

しかしながら、現実の測定データは必然的にノイズに 起因する誤差が含有し、ベクトル場の完全に一意的な可 視化画像は得られないが、可視化画像の固有パターンは 殆ど一致することを報告する.

\section{2. 基準座標系の定義}

\section{1 基準座標}

まず、基淮座標の概念を述べる．Fig. 1(a)に示した 2 ベクトルは一見すると異なるべクトルと見なされる。こ れは、我々が暗然に基準座標を図が描かれている枠と仮 定するためである。しかし、Fig.1(b)に示すように基準 座標軸を考えると雨者は同じベクトルであることが分か る.このように一見すると異なるベクトルも、ある基準 座標を導入することで、同一ベクトルと判断することが 可能となる.よって、ベクトル場は常に基準座標を勘案 しなければ議論できない，換言すれば、べクトル場に置 ける議論は同一基準座標系で為されなければ無意味であ る.
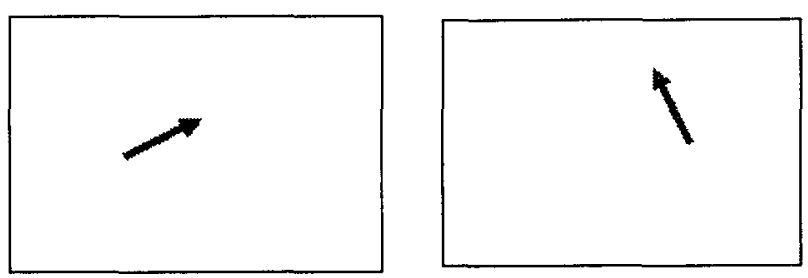

(a) Arbitrary Vectors
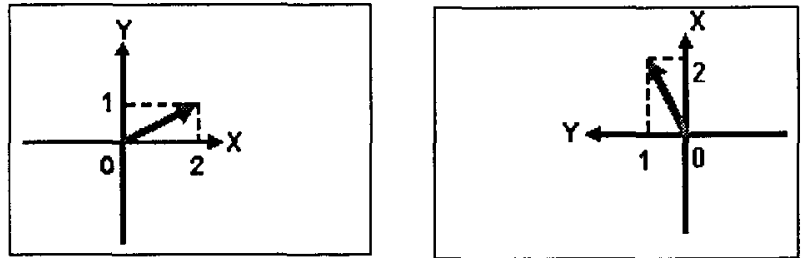

(b) Introduction to Reference Coordinate System Fig. 1 The Concept of Reference Coordinate System

\section{2 基準座標軸の決定}

さて、スカラー場、例えば大気圧の分布などでは、絶対 的なゼロ点が真空として自動的に定まる．他方、ベクト ル場では絶対的なゼ口点若しくは基準方向が自動的に定 まらない，これは、ベクトル場には任意のスカラー場 $\phi$ に起团する発散的ベクトル grad $\phi$ が存在し得ることに 起因する.すなわち、べクトル場は何らかの形で Gauge を決めない限り基準座標が決まらないことを意味する。

本稿では、ベクトル場の具体例として磁界系を考える. 3 次元の磁界分布は任意の局所座標系で測定可能である. 一般にベクトル場に含有される発散的なベクトルの回転 演算はゼロとなる，才なわち、rot grad $\phi=0$ が恒等的に 成り立つ。

この関係を磁界系で考えると、磁界から電流を求める
演算となる。

変位電流が無視できる準静的な Maxwell の方程式の、 磁界 $\mathbf{H}$ と電流密度 $\mathbf{J}$ の関係を表す方程式より、

$$
\nabla \times \mathbf{H}=\mathbf{J}
$$

であるから、磁界 Hの回転演算は電流密度ベクトル J を与える。この電流密度べクトル Jにはスカラーポテン シャル に決まる、したがって、電流密度ベクトルJからべクト ル場の基準座標を決定すればよいことが判る。磁界が $X$ 、 $y 、 z$ の 3 成分からなるから、電流密度べクトル $\mathbf{J}$ も $x 、 y 、$ $z$ の 3 成分からなる. 何れの電流密度成分も一意的に決 まるため、全ての電流べクトル成分を計算する必要は無 い.ここでは、磁界の $z$ 方向成分のみを考える。式(1) は、 $\mathrm{H}_{z}$ を磁界の $z$ 方向成分、 $\mathbf{i}, \mathbf{j}, \mathbf{k}$ をそれぞれ $x 、 y, z$ 方向の単位ベクトルとして、

$$
\begin{aligned}
\nabla \times \mathbf{H} & =\left[\begin{array}{ccc}
\mathbf{i} & \mathbf{j} & \mathbf{k} \\
\frac{\partial}{\partial x} & \frac{\partial}{\partial y} & \frac{\partial}{\partial z} \\
0 & 0 & H_{z}
\end{array}\right] \\
& =\left(\frac{\partial H_{z}}{\partial y}\right) \mathbf{i}-\left(\frac{\partial H_{z}}{\partial x}\right) \mathbf{j} \\
& =\mathbf{J}
\end{aligned}
$$

で与えられる，すなわち電流密度 $\mathbf{J}$ は $\mathrm{H} Z$ に直交する $x$. $y$ 方向成分のみとなる。

磁界の $z$ 方向成分 $\mathrm{H}_{z}$ の回転演算によって得られた電 流ベクトルにより、基準座標を決定する，本論文では、 得られた電流ベクトルの全てのベクトル和を取り、その 総和ベクトルの方向を基準座標系の $\boldsymbol{x}$ 軸と定める.また、 ベクトル和には互いに打ち消し合い、その結果零ベクト ルになる場合もある.このような場合には、 $\boldsymbol{x}, \boldsymbol{y}$ 軸方向 单位ベクトルと、各電流ベクトル間で内積演算を行い、 内積の最も大きい心゙クトルの向く方向を基準座標系の $\boldsymbol{x}$ 軸と定める。

基準座標系の $\boldsymbol{x}$ 軸を上述の方法で定め、 $\boldsymbol{z}$ 軸は测定面 に対して垂直方向であるから、y軸は式(3)を満たすよう に定められる.

\section{$\mathbf{Z}=\mathbf{X} \times \mathbf{Y}$}

Fig. 2 は上記の方法で決定された基準座標軸の例を示す.
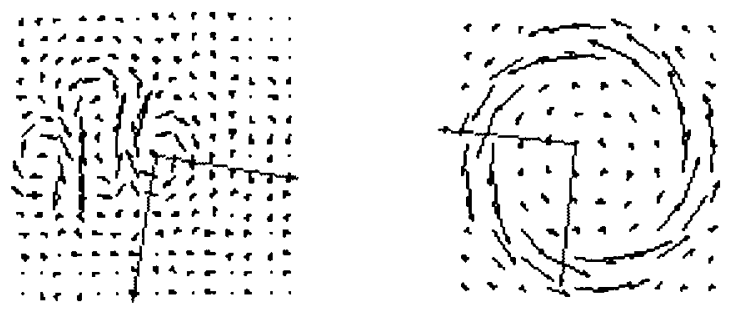

Fig. 2 The Example of Reference Coordinate System 


\section{3 基準座標系への投影}

予め局所座標系で測定した磁界の $\boldsymbol{x}, \boldsymbol{y}$ 成分を基淮座標 系へ投影し、基準座標系の磁界の $\boldsymbol{x}, \boldsymbol{y}$ 成分を求める。測 定した磁界の $x, y$ 成分による二次元ベクトルを $\mathbf{H} x y$ と する. $\mathbf{H} x y$ と基準座標系の $\boldsymbol{x}$ 軸とのなす角を $\theta$ 、

$\mathbf{H} x y$ の $x, y$ 成分、寸なわち測定した磁界の $\boldsymbol{x}, \boldsymbol{y}$ 成分をそ れぞれ $\mathrm{H}_{X}, \mathrm{H}_{Y}$ とすると、基準座標系の磁界の $\boldsymbol{x}, \boldsymbol{y}$ 成分、 $\mathrm{H}_{R X}, \mathrm{H}_{R Y}$ は、

$H_{R X}=|\mathbf{H} x y| \cos \theta=\sqrt{{H_{X}{ }^{2}+{H_{Y}}^{2}}^{2}} \cos \theta$

$H_{R Y}=|\mathbf{H} x y| \sin \theta=\sqrt{{H_{X}{ }^{2}+H_{Y}{ }^{2}}^{2}} \sin \theta$

と求めることができる．Fig. 3 は基準座標系へ投影する 概念図を示す。

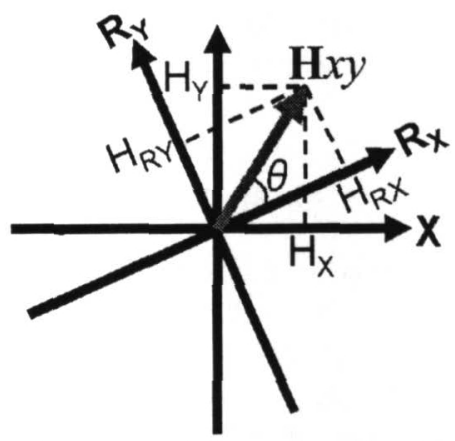

Fig. 3 Projection to the Reference Coordinate System

\section{3. 基準座標系による磁界分布の可視化}

\section{1 磁界分布のカラーイメージ生成}

磁界の各直交成分が $x, y, z$ 方向について得られている 場合、それぞれを光の R(Red),G(Green),B(Blue)成分に 対応させることで磁界分布をカラーイメージとして表現 することができる．この場合、以下に示寸式(5)の条件を 満たすように、各成分の最大值を 1 に正規化する必要が ある。

$0 \leq f_{r}\left(x_{i}, y_{i}\right) \leq 1$,

$0 \leq f_{g}\left(x_{i}, y_{i}\right) \leq 1$,

$0 \leq f_{b}\left(x_{i}, y_{i}\right) \leq 1$,

$i=1,2, \ldots, m, \quad j=1,2, \ldots, n$,

(5)式で、 $f_{r}, f_{g}, f_{b}$ はそれぞれ $\mathrm{R}, \mathrm{G}, \mathrm{B}$ 成分を与える関数 であり、 $m, n$ は画像の $x, y$ 方向の画素数である. Fig. 4 は、磁界の $x, y, z$ 方向成分、およびそれらを光の $R, G, B$ に対応させたカラーイメージの 1 例である.

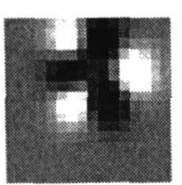

(a)X Comp.

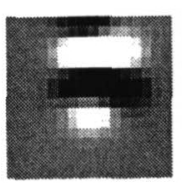

(b)Y Comp.

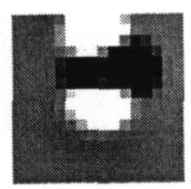

(c)Z Comp.

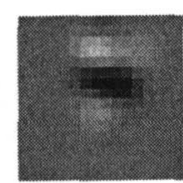

(d)Color

Image
Fig. 4 Magnetic Field Components and Color Image

\section{2 基準座標系の磁界分布画像生成}

シミュレーションによって得られた局所座標系の 3 成 分磁界を基準座標系へ投影し、磁界ベクトル分布の可視 化画像を生成する.Fig. 5 は、磁界測定の局所座標系を $90^{\circ}$ 毎に変更した場合に得られる磁界ベクトル分布の 可視化画像と画像を構成する $R, G, B$ 成分のヒストグラ 厶を示す. Fig. 5 で、左端、中心、右端の図は、それぞ れ局所座標系、基準座標系における磁界ベクトル分布の 可視化画像であり、さらに基準座標系における磁界べク トル分布の可視化画像を構成する R,G,B 成分のヒストグ ラムである. Table 1 は、Fig. 5 の基準座標系における磁 界ベクトル分布の可視化画像で、(a)の画像と各画像との 相関係数を示したものである. Fig. 5、Table 1 から、基 準座標系に投影することで、測定時の局所座標系に依存 しない磁界ベクトル分布の可視化画像が生成可能である ことが分かる.
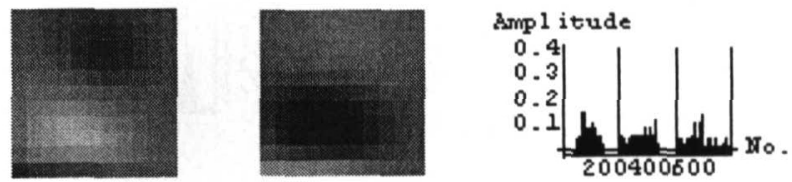

(a) $0^{\circ}$
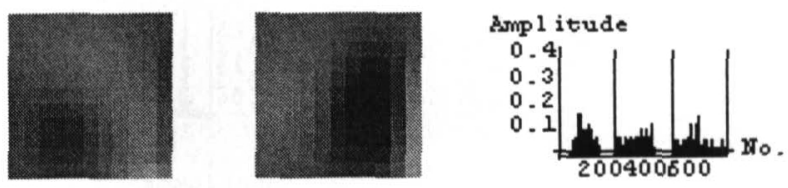

(b) $90^{\circ}$
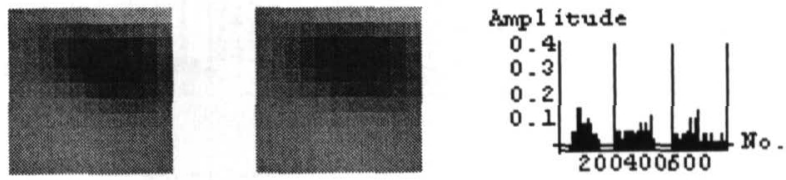

(c) $180^{\circ}$
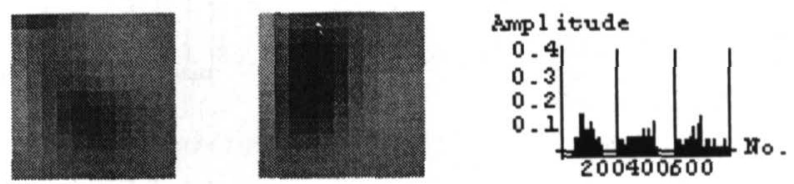

(d) $270^{\circ}$

Fig. 5 Visualizing Images of Magnetic Field Distributions in Reference Coordinate System (Simulation)

Table 1 Correlation Coefficient (Simulation)

\begin{tabular}{|c|c|c|c|}
\hline & $90^{\circ}$ & $180^{\circ}$ & $270^{\circ}$ \\
\hline $\begin{array}{c}\text { Reference } \\
\text { Coordinate System }\end{array}$ & 0.9994 & 09996 & 0.9994 \\
\hline
\end{tabular}

次に、実験によって得られた磁界ベクトル分布を用い て、基準座標系における磁界ベクトル分布の可視化画像 を生成する．実験は、供試コイルに $0.5 \mathrm{~A} 、 10 \mathrm{kHz}$ の電 流を通電し、その直上をソレノイド型サーチコイルで誘 起電圧を測定し、誘起電圧を積分して磁界を求めた。測 定点数は各成分ともに縦 11 点、横 11 点測定である. 
Fig. 6 は、上段左から供試コイル画像、磁界ベクトル分 布の可視化画像およびそのヒストグラム、下段左から基 準座標軸、基準座標系における磁界ベクトル分布の可視 化画像およびそのヒストグラムである.

基準座標系において、磁界ベクトル分布の可視化画像 は測定方向に依存しない可視化画像が生成されなければ ならない。しかし、実際の実験値を用いた基準座標系の 磁界ベクトル分布の可視化画像はヒストグラムから分か るように、測定方向を変えた場合、色成分の変化が見ら れる.これは基準座標が磁界測定時のノイズの影響を受 けていることに起因する.
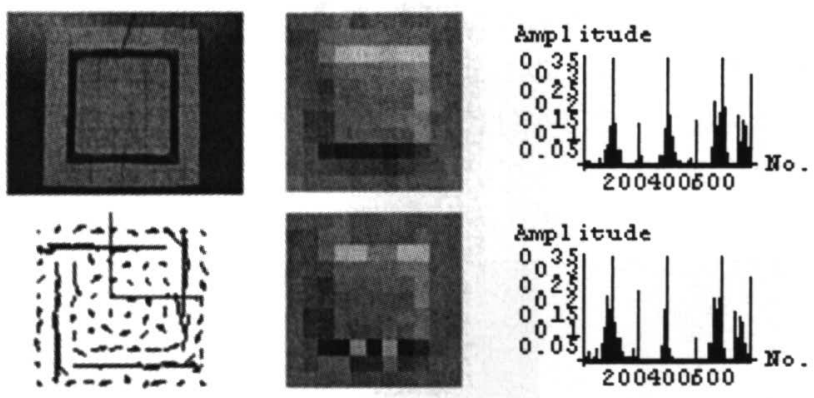

(a)Square1
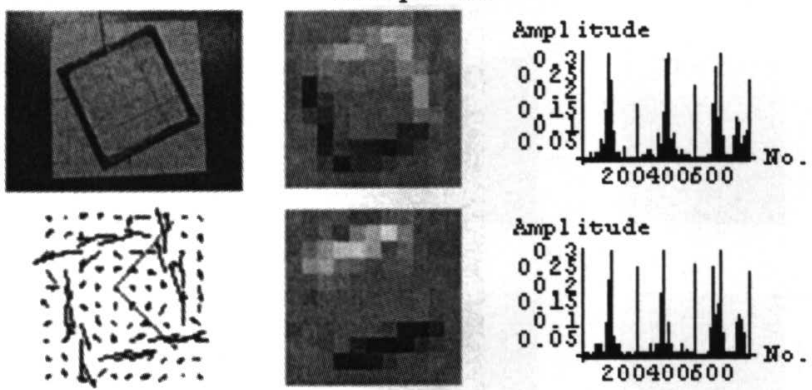

(b)Square2
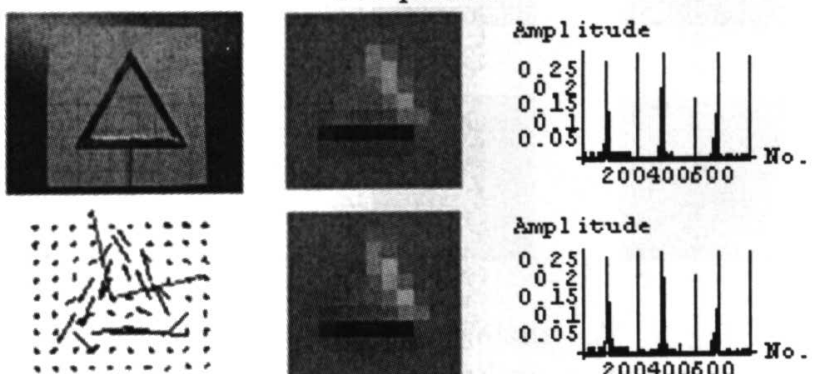

$\because \ldots . \cdots$

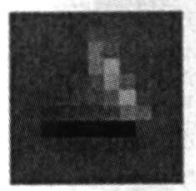

Ampl itude

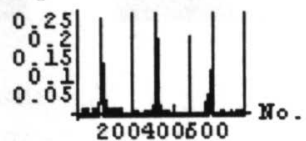

(c)Triangle1
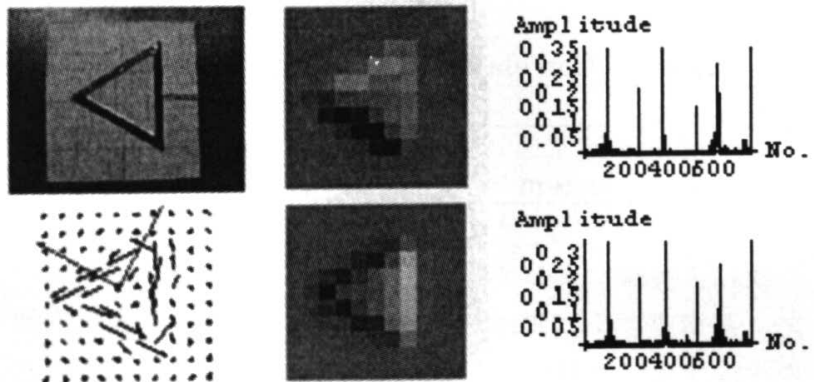

(d)Triangle2

Fig. 6 Visualizing Images of Magnetic Field Distributions in Reference Coordinate System (Measured Value)

\section{4.まとめ}

本論文では、磁界分布可視化法の一方法を提案し、我々 が提案してきた、磁界の $x 、 y 、 z$ 成分をそれぞれ光の $\mathrm{R}, \mathrm{G}, \mathrm{B}$ 成分に対応させて可視化する手法の問題点の解決 を試みた。

ベクトル場の Gauge 理論から、電流ベクトルを用いて 定めた基準座標系を導入し、シミュレーションにおいて は測定方向に依存しない磁界分布可視化画像が生成可能 であることを示した。しかし、実際の実験においては、 測定時のノイズの影響を受け、正しい基準座標が得られ ず、磁界ベクトル分布の可視化画像が完全に一意的にな らないことが判明した。

しかしながら、ベクトル場から可視化画像を生成する 場合、従来用いられた拘束条件を必要とせず、ベクトル 場の可視化画像が生成可能であることを理論的に証明し た．残る課題は磁界測定におけるノイズを如何に削减す るかにある。

\section{考 文 献}

1）若林健一、早野誠治、斎藤兆古：ウェーブレット変換を用 いた画像の固有パターン認識、可視化情報学会誌、Vol.20, No.1 (2000) pp.133-136.

2）佐藤隆紀, 早野誠治, 齋藤兆古:動画像認識手法を用いた電 磁界系非破壊検查, 電気学会基礎 - 材料 - 共通部門大会, 469 (2002 年 9 月). 